\title{
Fluctuating maximal God
}

\section{Anne Jeffrey $^{1}$ (i) $\cdot$ Asha Lancaster-Thomas ${ }^{2}$ D $\cdot$ Matyáš Moravec $^{3}$ (i)}

Received: 17 December 2019 / Accepted: 25 February 2020 / Published online: 3 March 2020

(c) The Author(s) 2020

\begin{abstract}
This paper explores a variety of perfect being theism that combines Yujin Nagasawa's maximal God thesis with the view that God is not atemporal. We argue that the original maximal God thesis still implicitly relies on a "static" view of divine perfections. Instead, following the recent re-evaluation of divine immutability by analytic philosophers, we propose that thinking of divine great-making properties (omnipotence, omniscience etc.) as fluctuating but nevertheless remaining maximal either for every time $t$ or across all times strengthens the original maximal God thesis. Furthermore, we show that "temporalising" Nagasawa's maximal God and adopting what we call the fluctuating maximal God thesis provides more effective ways of responding to objections to perfect being theism, in particular, the argument from evil and some conceptual problems pertaining to the Incarnation. Finally, we demonstrate that our proposal is compatible with Christian Scriptures and coheres with numerous biblical passages better than Nagasawa's original proposal does.
\end{abstract}

Keywords Maximal God · Perfect being theism · Immutability · God and time · Problem of evil

\section{Introduction}

Yujin Nagasawa (2017) has recently proposed a radical thesis - the maximal God thesis-to overcome many of the objections to perfect being theism:

Matyáš Moravec

mm2153@cam.ac.uk

Anne Jeffrey

Anne_Jeffrey@baylor.edu

Asha Lancaster-Thomas

asha.lancaster-thomas@cantab.net

1 Baylor University, Waco, TX, USA

2 University of Birmingham, Birmingham, UK

3 University of Cambridge, Cambridge, UK 
Maximal God thesis $=$ God possesses the maximal consistent set of the greatmaking properties power, knowledge, and benevolence.

One potential problem with Nagasawa's account is in explaining how such a concept of God can overcome all objections while retaining the precise unique set of these attributes. We propose that perfect being theists can respond to this problem as well as all the objections the maximal God thesis is supposed to defuse by denying that the degrees of the great-making properties composing the maximal set are necessarily the same at each point in time. We postulate a "fluctuating maximal God"a God whose degrees of power, knowledge, and benevolence may change over time as long as the set of these is maximal in its axiological value.

\section{Perfect being theism and the maximal God thesis}

Based on the premise that "God is the being that has the maximal consistent set of knowledge, power, and benevolence" (Nagasawa 2017, p. 104), Nagasawa's maximal God differs radically from traditional versions of perfect being theism. Although it retains the idea that God is the greatest metaphysically possible being, this "Neo-Anselmian" approach rejects the inference from this claim to the idea that God has knowledge, power, and benevolence to their intrinsic maxima (Nagasawa 2017, p. 93; Amini 2016). A major advantage of the maximal God thesis is that it can respond to traditional attacks on perfect being theism simultaneously—by replacing the omni God thesis (i.e., the thesis that God possesses the individual great-making properties to their intrinsic maxima) with the more modest claim that God is perfect, or unsurpassable, insofar as God possesses the maximal consistent set of power, knowledge, and benevolence. Moreover, Nagasawa is quick to emphasise that the maximal God thesis remains impartial about whether or not God is an omni God: the two theses are fully compatible.

Discussing his motivations for the maximal God thesis, Nagasawa constructs a classification system that categorises the abundance of objections that have been posed against perfect being theism. The objections can be sorted into three types: "arguments that purport to show the internal incoherence of God's individual properties' (Type-A); 'arguments that purport to show the mutual inconsistency between God's properties' (Type-B); and 'arguments that purport to show the mutual inconsistency between the set of God's properties and a certain fact about the actual world' (Type-C)" (Nagasawa 2017, pp. 82, 84-5). Type-A arguments aim to demonstrate that the individual properties God possesses are internally inconsistent. Arguments such as the classic paradox of whether God can create a stone that $\mathrm{He}$ cannot lift fall into this category. Type-B arguments aim to show that the entire set of God's properties is mutually inconsistent. The question of whether an omnipotent God, who is also omnibenevolent, could torture children, for example, fall into this category. Type-C arguments aim to show that the attributes God possesses are inconsistent with some states of affairs that obtain in the actual world. The problem of evil is one example of an argument of this type. Defenders of perfect being theism have thus far attempted to rebut objections such as these on what Nagasawa refers to 
as a "case-by-case" basis. This tactic involves refuting every objection that is raised to perfect being theism individually. Nagasawa suggests, however, that this is not the most resourceful tactic available to the perfect being theist: "[ $\mathrm{t}]$ he most obvious problem with the case-by-case approach is that, whether or not the individual responses to these arguments ultimately succeed, it is not very efficient as a defence of perfect being theism." (Nagasawa 2017, p. 90) Once we have effectively sorted arguments against perfect being theism into types $\mathrm{A}, \mathrm{B}$, and $\mathrm{C}$, we might consider what assumption they all share in common. If there is such an assumption and the perfect being theist can reject it, then she can defeat all three types of arguments at once.

Employing this strategy, Nagasawa schematises arguments of every type in one more general argument:

(1) If perfect being theism is true, then the perfect being thesis is true.

(2) If the perfect being thesis is true, then the omni God thesis is true.

(3) If the omni God thesis is true, then God is an omniscient, omnipotent, and omnibenevolent being.

(4) There cannot be an omniscient, omnipotent, and omnibenevolent being.

(5) Therefore, the omni God thesis is false.

(6) Therefore, the perfect being thesis is false.

(7) Therefore, perfect being theism is false. (Nagasawa 2017, pp. 91-2)

To construct a forceful and efficient defence against any argument of this form, Nagasawa explains, we need only reject (2): that is, we can remove the omni God thesis from the equation, therefore freeing perfect being theism from the shackles of the omni properties.

Nagasawa also addresses several large objections to the maximal God thesis in turn. One main objection he considers runs as follows:

One might reject my maximal God approach by saying that it is unreasonable to think that there is a single combination of knowledge, power, and benevolence that undermines all Type-A, Type-B, and Type-C arguments against perfect being theism. For example, it might be the case that perfect being theists need God to have more knowledge and less power in response to one argument but more power and less knowledge in response to another. (Nagasawa 2017, p. 106)

According to this objection, the onus is on the maximal God theist to demonstrate how certain degrees of power, knowledge, and benevolence can defeat every significant objection to omni God perfect being theism.

This objection is not unrelated to another problem: The maximal God thesis seems to invite polytheism. In order for a being to qualify as God, it must have the highest combined knowledge, power, and benevolence compossible. Imagine that one being has 29 units of great-making properties in total: 9 of knowledge, 10 of power, and 10 of benevolence. A second being might have 10 of knowledge, 9 of power, and 10 of benevolence and so simultaneously qualify as God; a third might 
have 10 of knowledge, 10 of power, and 9 of benevolence (Nagasawa 2017, pp. 110-111). Nagasawa offers the following defence regarding polytheism: It could be the case that only one combination of degrees of great-making properties can yield the sum of 29. Additionally, the different great-making properties might have different axiological values such that the simple sum of degrees of great-making properties does not actually identify the overall greatness of the being. However, this response to the polytheism objection could exacerbate the first objection regarding one unique specification of great-making properties dealing with all three types of objections to perfect being theism. For example, stipulating that one great-making property, like benevolence, holds more axiological weight than the other limits possible responses to certain Type- $\mathrm{C}$ arguments. It commits the theist to the idea that God cannot anticipate what a hate-filled dictator will freely choose to do, and so that God has the power to stop such a villain from committing genocide.

In the next sections, we argue that Nagasawa's main idea, when combined with the thesis that God is temporal and in some way mutable, could avoid these criticisms more effectively and offer many of the benefits promised by the maximal God thesis.

\section{Fluctuating maximal God}

Putting Nagasawa's thesis aside for the time being, observe that perfect being theism has traditionally tended to include on its list of divine attributes not only omnipotence, omniscience, and omnibenevolence, but also immutability. Divine immutability in the strong sense (the claim that God does not undergo any changes whatsoever, be it changes of His nature or mere "Cambridge" changes) has frequently been coupled with the idea of God being timeless (as opposed to God being everlasting, i.e., existing through time but simply never beginning to exist or never ceasing to exist (Swinburne 2016, p. 228)). Nevertheless, recent years have also seen the development of arguments for rejecting or downgrading divine immutability and timelessness to preserve logical coherence (see for example Mullins 2016), parallel to Nagasawa's project of redefining the core of perfect theism by modifying the traditional tripartite omni God thesis. Many reasons for regarding traditional timelessness with suspicion have been cited: its incompatibility with divine personhood or causality in time, to give just two examples. Although we suspend judgement about which of the two options of framing God's relation to time outlined above (temporality/atemporality) is the better one, they both seem to be live options in contemporary scholarship.

Now, suppose, for the sake of argument, that a perfect being theist might have independent reasons to reject strong immutability. Furthermore, observe that the picture of the maximal God proposed by Nagasawa leaves completely undecided the temporal indexication of the maximally consistent set of great-making properties. When does God possess the maximally consistent set of properties? Does He possess these in eternity? Do we simply gather the information we have about God's nature and His dealings with the world and then, at the end of time, calculate the contents of the maximal set? Or is He greatest at every moment in time? In fact, 
the picture that emerges from Nagasawa's proposal is one of God possessing the maximal set of great-making properties timelessly and/or immutably, in somewhat of a static manner - a picture not explicitly affirmed by Nagasawa, but perhaps still lurking in the background, smuggled in as a residue of traditional perfect being theism. The original maximal God could, therefore, be designated as a "static maximal God" (SMG).

Denying Nagasawa's SMG, we propose the "fluctuating maximal God" (FMG) thesis, which can be summarised as follows: the degrees of divine knowledge, power, benevolence (and perhaps others) fluctuate in the course of time, while their sum, nevertheless, remains maximal. Such a definition leaves open what the specific degrees of individual properties are at particular times or whether one great-making property has more axiological weight than others. At $t_{1}$ God's knowledge can be greater than at $t_{2}$, if this, for example, allows for God to be more benevolent at $t_{2}$ than at $t_{1}$. We, therefore, can accept the idea that there is not a "single combination of knowledge, power, and benevolence that undermines all Type-A, Type-B, and Type-C arguments against perfect being theism" while holding that the maximal God strategy does enable one to defend perfect being theism from all three types of arguments.

Prima facie, one might protest that the value exhibited by a being cannot vary simply by time because temporal location alone can never be a basis for a normative difference. If the degree of one of God's great-making features fluctuates, what motivates the fluctuation? We contend that facts about the world are the catalysts for these fluctuations. There are two options to explain the causal relationship between God's fluctuations and facts about the world. The first is that facts about the world cause God to change in the way that the fact of seeing a lion causes one to feel afraid; God may have a constant disposition to respond in appropriate ways to certain events such that the occurrence of those events activates the disposition. The second is that facts about the world are related to the degrees of God's attributes by a necessitating logical relation in the way that a decrease in the speed of a car "causes" an increase in the time it takes to travel a distance.

Let us be clear when we say that although God's overall value is intrinsic, the great-making attributes themselves are relationally valuable. ${ }^{1}$ So, although the degrees of each attribute that constitute the axiological value do change, God's

\footnotetext{
1 It is important to note that by "intrinsic value" we mean final, or non-instrumental, value (rather than an extension of the Lewisian formula "in virtue of itself and nothing else"). Otherwise, assuming a Lewisian meaning of "intrinsic" and applying it to value, one might worry that a relational value would thereby fail to be intrinsic. The proposal under consideration states that God possesses properties that are intrinsically valuable - valuable for their own sake and not for the sake of anything else. The degree to which God possesses any of these given properties at a point in time will depend on what is valuable in relation to states in the actual world. Thus it is not that the property possesses value only relative to us, or some fact about the world, but that the property possesses final or intrinsic value and the degree to which the greatest possible being will possess that property at a time does depend on the facts in the world. Furthermore, the issue of how to quantify the perfections in the first place is not a problem specific to our conception of the fluctuation of individual great-making properties; the onus of explaining the nature of these trade-offs is on the defender of the original SMG thesis.
} 
overall axiological value —or absolute greatness — does not change. So the fluctuation of degrees does not entail a fluctuation of worth. ${ }^{2}$

How does our proposal fare with regards to the objections that Nagasawa's SMG was supposed to resolve in the first place?

First, unsurprisingly, temporalising the maximal God thesis leaves intact its ability to rebut Type-A arguments. Maximal God theism says that God is always the greatest metaphysically possible being, where members of the set of God's greatmaking properties are individually metaphysically possible at the very least. Again, this constraint operates if God is in time as well. On this version, we simply say that God is the greatest metaphysically possible being and so at each time $t$, the greatmaking features God possesses at that time must meet this requirement of metaphysical possibility. It should also be noted that our view, strictly speaking, does not even require God's features to fluctuate; the FMG permits these fluctuations but does not demand them. If it turns out that the best combination of properties is the same at all times, then so be it.

Equally, the power to respond to Type-B arguments also remains unaffected: the FMG allows (but does not require) there to be different configurations of great-making properties at different times. In the absence of facts about the world affecting the composition of the maximal set-for otherwise the Type-B argument would qualify as a Type-C argument which we will turn to shortly-it is not obvious what would actually motivate these fluctuations. In any case, they are not disallowed by the FMG and all of their numerous re-combinations are still constrained by the consistency requirement. Even though — again, in the absence of facts about the world- the maximal God theist might not need this feature of the FMG, it is there as a theoretical possibility, carried over from the SMG and multiplied by being indexed to every time.

However, the FMG does make a crucial difference to the mutual consistency of two or more attributes once we factor in facts about the world. This brings us directly to Type-C arguments, where the FMG offers immense argumentative power. According to one Type-B argument Nagasawa mentions (Nagasawa 2017, p. 85), God's omnipotence and omnibenevolence are mutually incompatible. For if God is all-loving, God cannot sin or wrong other persons. This obviously places a constraint on what God is able to do, that is, God's power. Thus the opponent of the Anselmian omni God concludes that such a God does not exist. Nagasawa can avoid this by ratcheting down the degree of God's power such that it is compatible with the highest degree of love. Now compare two beings: the first being is such that its degrees of power and love never fluctuate and the second is such that its degrees of

\footnotetext{
${ }^{2}$ Under this model, God is necessarily the greatest possible being. So, when a fact about the world indicates that God's great-making features' degree(s) must fluctuate, then God must change accordingly to continue being the greatest possible being. We can schematise this view as follows:

(1): God is the greatest possible being.

(2): At time $t$ God must change to remain the greatest possible being.

(3): So God must change at time $t$.
} 
power and love can fluctuate. ${ }^{3}$ Now, throughout time there will be changes in the world on which the opportunity for God to sin supervenes. To simplify, say that for every act that God cannot perform, God's power is lowered one degree. For each act of sin God cannot perform, then, we lower God's power a degree. The first being will have its degree of power for each time fixed by the sum of all the acts it cannot perform throughout time, whereas the second being could have a very high degree of power at times where there is no opportunity to sin and a lower degree of power at times where an act of sin is available but not possible for that being. So, which being is better? It seems plausible that the second one is better. For over the course of its career it has had higher degrees of power. For instance, if there is a stretch of time in which no human persons exist, no acts of sin involving wronging of human persons are available. Thus there is no possibility at those times that the second being cannot actualize, and in virtue of which it lacks a degree of power. At those times, the being will have much more power than the first being, whose degree of power is fixed by all the future times at which human persons do exist and afford chances for sins of wronging them.

In more abstract terms, Type- $\mathrm{C}$ arguments take one or more facts from the totality of facts about the actual world and show that such facts are incompatible with perfect being theism. At a purely conceptual level, observe the following:

(1) Type-C arguments are used to show the incompatibility between the set of God's great-making properties and a certain fact about the actual world.

(2) The particular combination of God's great-making properties is, on the FMG thesis, dependent on facts obtaining at times of the actual world.

(3) The actual world exists in time, i.e., every fact about the actual world ${ }^{4}$ obtains at a particular time.

This means that, in a way, any potential incompatibility advanced by the opponent of the SMG thesis between a particular combination of God's properties and a fact about the actual world is, itself, related to a particular time $t$. Recall again the objection discussed by Nagasawa that "it is unreasonable to think that there is a single combination of knowledge, power, and benevolence that undermines all Type-A, Type-B, and Type-C arguments." Now, on the temporal version of maximal God theism, we need not accept that God displays a single combination of knowledge, power, and benevolence. But a Type-C argument will posit that some combination of power, knowledge, and benevolence is required due to facts about the actual world, and these facts will be indexed to a particular time. More specifically, the facts about the actual temporal world that figure in Type-C arguments are indexed to

\footnotetext{
${ }^{3}$ For the time being, put to the side the fact that if this ability to fluctuate is a power, it would make the second being greater vis à vis degrees of power.

${ }^{4}$ Our discussion excludes general facts that obtain at all times (e.g., the fact that there is no Santa Claus, which is true at every time $t$ of the actual world), since, by their nature, they are included in every set of facts at every time $t$ and thus do not make a difference to the maximal set at every time $t$.
} 
times and so the validity of the arguments will depend on premises that index God's properties to times.

Schematically, an objector to perfect being theism argues:

(1) The world is $x$ way at $t$.

(2) The world's being $x$ way is incompatible with the existence of the omni God.

(3) Therefore, the omni God does not exist.

A more perspicuous argument will say, in premise 2, that the world's being $x$ way at $t$ is not compatible with the existence of the omni God at $t$, so the omni God does not exist at $t$. Similarly, she may argue more perspicuously against the SMG thesis:

(1) The world is $x$ way at $t_{1}$.

(2) The world's being $\mathrm{x}$ way at $t_{1}$ is incompatible with the existence of a being that has the maximal consistent set $\mathrm{S}$ of power, knowledge, and love.

(3) Therefore the being with the maximal consistent set $\mathrm{S}$ does not exist at $t_{l}$.

The FMG thesis leaves open the possibility that "the perfect being theists need God to have more knowledge and less power" in order to achieve maximal consistency with one fact about the world at $t_{1}$ and at the same time "more power and less knowledge" in order to achieve maximal consistency with a different fact about the world at $t_{2}$. And so the defender of the FMG thesis can accept (2) and (3) from above while concluding that God may still exist, for God may be the being that has $\mathrm{S}$ at $t_{2}$ but a different combination of degrees of great-making properties at $t_{1}$.

Ultimately, the FMG thesis is significantly more effective against Type-C arguments than the SMG thesis by claiming that contingent facts about the world can actually fix how God's great-making properties combine. Let us take the argument from evil to illustrate this. This argument, like all Type-C arguments, differs from Type-A and Type-B arguments because it does not focus on a solely logical issue of God's internal properties (which, for Nagasawa, are necessary and fixed). Nagasawa claims that the SMG theist need not worry about the problem of evil (or Type-C arguments in general) unless the contingent world facts seem hugely incompatible with God's nature:

The maximal God approach is in danger only if the argument from evil shows that the quantity and quality of evil in the actual world are so significant that we have to "compromise" God's knowledge, power, or benevolence to the extent that He can no longer be the being than which no greater is metaphysically possible. (Nagasawa 2017, p. 115)

Nagasawa thus places the onus on the Type-C arguer to provide examples of evil that are this extreme. Yet it seems that such examples do exist, examples in which reducing God's power to explain great evil in the world would render Him 
extremely weak. Nagasawa's response is to claim that at least the SMG thesis can account for evil more readily than the omni God thesis because:

Showing the quantity and quality of evil in the actual world are so significant that we have to "compromise" God's knowledge, power, or benevolence to such an extent is more demanding than showing that they are so significant that we have to "compromise" God's omniscience, omnipotence, and omnibenevolence. (Nagasawa 2017, p. 115)

Nagasawa ultimately admits that the SMG thesis might not be able to defeat the problem of evil without appealing to certain theodicies. Unlike the SMG theist's response, which is limited and relies on conjecture, the FMG thesis can offer a strong response to Type- $\mathrm{C}$ arguments like the problem of evil because it allows that contingent facts independent of the nature of God can affect God's attributes at one time, but they act as temporary metaphysical constraints on any being. So at any time, God refers to the axiologically best being in that world.

\section{Greatest at every time or greatest career?}

Before moving further, we need to return to an important ambiguity regarding the original formulation of the FMG. Recall that we defined the FMG as the claim that "the degrees of divine knowledge, power, benevolence (and perhaps others) fluctuate in the course of time, while their sum, nevertheless, remains the same." However, this formulation does not distinguish clearly enough between the following two claims:

Claim 1: The degrees of divine knowledge, power, benevolence (and perhaps others) fluctuate in the course of time, while their total sum for the totality of all times, remains maximal.

Claim 2: The degrees of divine knowledge, power, benevolence (and perhaps others), fluctuate in the course of time, while their total sum for every single time remains maximal.

The first claim can be designated as the "greatest career" approach; God does not have to be greatest at every single point of time, but, once His values for all times are added up, He "ends up" being the greatest. The second claim simply says that no matter what point of time we look at, and how many beings existing at that time we consider, God will always clearly come out as being the greatest. Claim 2 entails Claim 1 (since if God is greatest at every time, He is also greatest once these times are all added up), but not the other way around. Which one of these should the fluctuating God theist adopt?

Let us consider Claim 1 first and then observe if we gain any advantages by strengthening it to Claim 2. Claim 1 preserves the entire strength of Nagasawa's proposal. It simply specifies that its scope concerns all points of time conjointly. One 
of its rather troublesome consequences, however, is that it is in principle compatible with there being a time at which God is not the greatest possible being and thereby strengthens Nagasawa's original problem with polytheism. Whereas for the SMG thesis, the problem is that the maximal set may be exhibited by more than one being, for our proposal, this problem is multiplied, since there is a single maximal set like this for every point in time. At every point in time $t$, there exists a (different) possible world in which there is a being with a maximal set relative to $t$ but this maximal set consists in a different combination of degrees of the great-making properties. How can we guarantee that this is always the same being? We see at least three ways to respond to this problem:

First, we may simply concede that this is exactly the same problem that the original SMG thesis faces. Since our aim was not to find a response to every objection to Nagasawa's SMG thesis, but instead to consider resources for strengthening it in some respects, this problem simply ends up being carried over into the FMG thesis too. If the SMG thesis faces this problem, and our proposal "temporalises" Him, it should not be surprising that the problem itself reappears in a "temporalised form."

The second option is to concede that those different possible beings at different times are all God. But since the FMG thesis speaks about states of affairs maximally consistent with facts obtaining at times $t$ in the actual world, what happens in those possible worlds does not matter. If those possible worlds were actual, then the facts about the actual world would be different and so would the identity of the fluctuating maximal God. But possible worlds are merely possible so what happens in them does not matter. It has no significant bearing on what God is actually like, just like the counterpart of Hubert Humphrey who wins a presidential election in a faroff possible world does not matter for what Hubert Humphrey is actually like (Felt 1996, pp. 63-77; Kripke 1981; Lewis 2002; Robson 2011, pp. 55-75).

Thirdly, (and this is our preferred response), the problem might be neutralised by claiming that it is simply a semantic issue. To formulate this problem in a Kripkean language, the term "God" (or in our case, "fluctuating maximal God") is a rigid designator which refers to God, i.e., the being that has the maximal sum of great-making properties for all times conjointly. "God" can designate God, even if God changes, and even if a definition applying to the totality of times does not apply to Him at individual times. More importantly, it does not matter whether there is an actual being at time $t$ with a higher degree of greatness than God since God is the greatest for all times. One may still be the healthiest member of a given group of people (and referred to as "the healthy one") even when one is caught secretly smoking a single cigarette while the other compulsive smokers happen to be munching away on their salads. This move seems particularly desirable since it is available to the defender of the FMG thesis but not of the SMG thesis. Consider the following example. At time $t_{1}$ (say, at the time of the Flood), the degree of the maximally consistent set possessed by God is 27 , and this set is exhibited by God. At time $t_{2}$ (yesterday afternoon), the maximally consistent set is 29 and is again, exhibited by God. However, at $t_{2}$, the set amounting to 27 is exhibited by Archangel Gabriel. Does this mean that at $t_{1}$, it was the case that Archangel Gabriel would become God at $t_{2}$ ? Certainly not. The FMG thesis simply provides details of what is true of the being referred to by the rigid designator "God" 
at different points in time..$^{5}$ At $t_{2}$, God is still God, what happens at $t_{1}$ does not matter, since at $t_{2}$ the maximally consistent set is not the one exhibited by Archangel Gabriel.

How about Claim 2, i.e., regarding the FMG as attaching to every single time? We have been unable to find ways to make this stronger version of the FMG thesis coherent. There are two primary difficulties with Claim 2. First, on this reading, it seems very difficult to ensure that God be the greatest possible being at every time $t$ other than by fiat. How can we guarantee that Archangel Gabriel in the previous example would not qualify as "God"? And how can we guarantee that the situation described by the Archangel Gabriel example does not, in fact, obtain? Of course, the adherent to the Claim 2 version of the FMG thesis might raise the following methodological point: The SMG and FMG are intended to serve merely to shift the burden of proof onto the opponents to the maximal God approach-so one might envision sticking to Claim 2 and simply stating that the burden of proof is on the atheist to show that Archangel Gabriel on the scenario described earlier qualifies as God. While this is certainly true and the possibility of the Archangel Gabriel scenario obtaining does not destroy the coherence of the FMG qua Claim 2, it does seem to be an unwelcome consequence which FMG qua Claim 1 does not invite. If the FMG theist has other reasons to accept Claim 2 (although we do question these reasons, see below), then the Archangel Gabriel problem does not per se threaten the coherence of the FMG; but all other things being equal, the Archangel Gabriel consequence is avoided on Claim 1. Secondly, one might also run into difficulties trying to define what the "time" to which FMG is now supposed to attach, actually is: If "time" is understood as the "smallest unit of time," if there is such a thing (e.g., a chronon), then the FMG must be related to every single such unit of time. If "time" is understood as a temporal interval, the FMG can be limited either to a particular short interval ("the time of the Flood"), to a set of such intervals ("Israel's wanderings in the desert"), or, indeed, the interval stretching from the beginning to the end of time, which, in effect, means that Claim 2 converts itself to Claim $1 .^{6}$ The metaphysical consequences

\footnotetext{
5 One might also object that it could be true of someone else at a different point in time. For example, it might happen that at $t_{2}$ Archangel Gabriel exhibits the set with a total degree of 50, thus being maximal at $t_{2}$. The rigid designator "God" would thus pick out a being whose degrees of great-making properties were not maximal at $t_{2}$. There are prima facie three ways this objection may be responded to. First, the FMG thesis is a version of perfect being theism, therefore it does not permit the existence of a being greater than God for purely theological reasons-reasons quite independent of the formalisation of the FMG thesis itself. Second, the FMG thesis should be regarded as a description of God, not as a definition; we are therefore not making a claim about it providing necessary and/or sufficient conditions for divinity, but merely as giving details as to what God is like-details that the maximal God theist may then use in responding to all the various arguments against perfect being theism. Third, the response may be articulated in an Anselmian fashion in terms of God being "unsurpassed" and/or "unrivalled." We may argue, for instance, that although Gabriel's having a greater overall degree of great-making properties at one moment in time means God is "rivalled," it does not mean that He is surpassed since Archangel Gabriel is not a maximal being at every time $t$.

6 It might be argued that this worry is simply the result of formulating Claim 2 on the supposition that time is discrete instead of being continuous and that the problem can simply be resolved by reformulating Claim 2 in terms of "always" (as opposed to "at every time"). If we assume that "always" does not simply mean "the totality of all times" (otherwise it would simply be equivalent to Claim 1), the problem with indexing the degrees to the smallest units of time (e.g., chronons) indeed disappears. However, the problem of indexing these degrees to different intervals-for both continuous and discontinuous time admit of distinct intervals of different lengths - still remains and we can still legitimately worry about God being greatest at every (single) interval of time.
} 
of each of these options are also even further complicated by the fact that each of the formulations of "at the same time" would need to be relativised to a particular frame of reference and combined with a suitable temporal ontology: is Archangel Gabriel greater than God in one reference frame but not as great in a different one where God has already performed a particularly great action? Things could get messy. By contrast, sticking to Claim 1 gives the FMG theorist the possibility to either adopt an eternalist ontology of time (God is greatest with regards to the entirety of the spacetime block) or, if she wishes, the freedom to come up with ways to make Claim 2 coherent.

However, if the FMG theorist wishes and is able to make Claim 2 coherent, one might wonder why she might want to do so. Surely, allowing the possibility of there existing a being greater than God at certain points of time-implied by Claim 1 -is a slightly weird consequence, but perhaps not so much weirder than having a possible being at every point in time implied by Claim 2 . At some points in time, furthermore, it may be part of the divine providential plan to allow there to be a being greater than $\mathrm{He}$ is at those points in time. Such an option would not be available if we adopt Claim 2. Finally, the consequence of allowing there to be "short-term greater" beings than God in no ways affects the type of greatness for which God is worshipped: in the same way as a short bout of flu does not prevent us from ascribing invincible strength to an Olympic athlete. In view of the fact that there are no tangible advantages of Claim 2 over Claim 1 and the difficulties the articulation of Claim 2 is fraught with, we propose limiting FMG to the weaker Claim 1.

\section{Incarnation, evil, scripture}

Apart from preserving the strength of Nagasawa's SMG, the FMG also adds further and more powerful ways of responding to other problems which are more theological in nature. Typically, the perfect being theologian must offer different responses to questions, such as: How is the Incarnation logically possible? Why does God permit certain observed evils? and How do we reconcile perfect being theology with the picture of God as He is portrayed in Scripture? It is not clear that the typical answers exhibit any serious unity or coherence. For example, the perfect being theologian might defend a two-minds view to make sense of apparent logical inconsistencies in the doctrine that Jesus is God (e.g., that He is both limited in power, given His human nature, and unlimited in power, given His divine nature), but the two-minds view does not afford any solution to the problem of horrendous evils. Obversely, in order to respond to the problem of evil, a perfect being theist might argue that being omnibenevolent does not entail having a requiring reason to promote the well-being of every creature; but this argument does not give her any resources to solve the problems of logical inconsistency in the Incarnation or to explain God's apparently fluctuating emotional responses to the Israelites wandering in the desert (Murphy 2017, pp. 70-75). For these, she might have to adopt a free-will defence and a particular hermeneutical lens for interpreting the Bible.

This by itself is not a mark against such views. But it shows that such perfect being theists will trade simplicity in their account of the divine perfections for complexity elsewhere, especially in defending distinctively Christian views. 
While someone could complain that the FMG thesis adds unnecessary complexity to the picture of the divine perfections, this complexity could be a fair trade for theoretical power and simplicity when it comes to responding to challenges to Christian theism. If all one needs to answer these various challenges adequately is the FMG thesis, the theory, on the whole, will be more parsimonious.

Can the FMG thesis offer a response to the argument from evil? On the SMG thesis, we have to hold fixed whatever adjustment to the degrees of divine power, knowledge, and benevolence we make to explain the compossibility of God's existence and the presence of evils in the actual world. Suppose the defender of the SMG thesis says that God's power to prevent evils is limited while God's benevolence and knowledge are dialled up to the intrinsically highest degrees. Let us grant that any creature with more power than this would necessarily have less benevolence or knowledge. Now, add to this the observation that evils seem to differentially impact different persons, or even the same person through time. If God's power to limit those evils remains the same throughout time, why does God appear to intervene and prevent some evils and not others, when it looks like prevention would require roughly the same degree of power in those cases? For instance, God's degree of power, compossible with benevolence and knowledge, enables God to eliminate the Egyptian Pharaoh and his army during the Exodus; it is, then, unclear why those same degrees of benevolence and knowledge would not be compossible with a degree of power that would enable God to eliminate Hitler and the Nazi German army in World War II. The dialling down of some degree of a great-making feature must be consistent with both the evidence of evils that occur and evidence of divine prevention of other evils. If observed evils and prevented evils do not form a regular pattern, one easily explicable by the particular degree set of divine power, knowledge, or benevolence, this will detract from the power of the SMG thesis to allow a theist to respond to the problem of evil.

The FMG thesis circumvents this issue. For on the FMG thesis, we are free to claim that the degree of some great-making property fluctuates over time, as long as it is part of the maximal set of great-making properties composing God's entire career. At the time of the Exodus, God's power is dialled up to a high enough degree that God may part and re-gather the Red Sea. Perhaps the degree of God's knowledge is limited at this time, but this does not affect God's successfully saving Israel. We can imagine that, due to there being few metaphysical possibilities of harm coming to Israel immediately following the swallowing up of Pharaoh's army, God can base His plan to bring Israel to safety on a wager, using probabilistic beliefs instead of knowledge. Thus God cedes knowledge in order to gain power. We can tell another story for the case of Nazi Germany. Imagine the many battlefronts and enormous numbers of people involved make it important that God have more comprehensive knowledge to act wisely. Thus God sacrifices power to gain knowledge, and so fails to prevent some present evils to Jews and Allies. But perhaps if God had 
retained more power and abdicated knowledge, God would have exerted great force to do something where the probability of a worse disaster was fairly high. ${ }^{7}$

The attentive reader now can anticipate what we will say about the Incarnation. The FMG thesis fits well with a Christology on which the Second Person of the Trinity, the Son, genuinely sacrifices some degree of attributes such as knowledge in taking on human nature, even if only temporarily (Evans 2009; Forrest 2000).

Notice that contemporary kenoticism, which has seen revival of interest among Christian scholars, fits with the FMG thesis quite naturally. Contemporary kenoticists claim that the Second Person of the Trinity gives up some degree of power and knowledge, out of love, in order to assume a human nature. Instead of saying that the Second Person loses the divine attributes, we can say that the degree of the Second Person's knowledge, power, or benevolence changes throughout the life of Christ. The Second Person might exhibit love to the intrinsic maximum because He has need of fellow human persons, is physically engaged with them, and sacrifices degrees of power and knowledge for the sake of uniting Himself to human nature for our salvation. If that intrinsic maximum is sufficiently high, then the Second Person could have very low degrees of knowledge and power while still achieving the maximal sum required by the FMG thesis.

It should come as no surprise that kenoticism coheres with the FMG thesis; increased comfort with the idea that "God does indeed change in significant respects, but never in contradiction to God's character," as one author puts it (Thompson 2006, p. 106), paved the way for the revival of kenotic theology, and also motivates our exploration of the FMG thesis. And in fact, kenotic theologians can respond to Type-C objections to perfect being theology in virtue of certain divine attributes being temporally indexed. Pawl has shown that kenotic theology also has the resources to avoid the logical objection to the Incarnation by insisting on the irreducibility of tense in the copulas joining certain predicates to the Second Person (Pawl 2016). The kenotic theologian ought to say, according to Pawl, that the Second Person was impassible and is passible, and that from this conjunction we cannot derive the logical contradiction that the Second Person is both impassible and passible (Pawl 2016, p. 177). In sum, the FMG thesis should have special appeal to the Christian theist with sympathy for kenoticism. For the FMG thesis suggests a broader framework for thinking about divine attributes that makes sense of their way of understanding the record of Christ's earthly life as well as their preferred solutions to the logical problem with the doctrine of the Incarnation (See Morris 1989).

\footnotetext{
7 It might still be objected that there is something odd about a theory which asserts that God intentionally fluctuates His relevant attributes in such a way that He can be excused from allowing evil instead of preventing it. However, the example above serves merely as an illustration of how to make the different facts at different times compatible with the degrees of great-making properties. We do not here give a theory which would explain the grounds for the fluctuations; they might be intentional exercises of divine agency or contingently necessary responses to facts in the world given the maximal greatness of God (see above). The aim of the FMG is simply to provide a coherent story about how the fluctuating facts about the world cohere with great-making properties. That's all that is needed to respond to the opponent of perfect being theism.
} 


\section{Objections and replies}

Nevertheless, despite the advantages outlined above, one might find two strong objections against our view. First, one might object that changes in the degrees of the various divine perfections would require an exertion of God's power. But it seems possible that at $t_{1}$, the degree of God's power is so low that God cannot effect an increase in power at $t_{2}$. How might the defender of the FMG thesis avoid this rather worrying possibility?

One possible response is to stipulate that God's power never dwindles to so low a degree that God loses the power to change the degree of the divine attributes at the next moment in time. Suppose each unit of God's power corresponds to a power to perform a particular action. What the defender of the FMG thesis must say, then, is that God's power never falls below a certain minimal level and that the power represented by the baseline level is the power to change the degree of God's great-making properties.

Another possible response is to say that God does not exert any power to affect the fluctuation in degrees of the great-making properties. One sense in which the FMG thesis might show that God is maximally great is that God exhibits all the possible combinations of great-making properties to differing degrees throughout human time. If God does this according to a plan, then the plan and overall power through time could together explain the fluctuations in degrees of properties, from the top-down, rather than the explanation for any given fluctuation being the properties possessed by God at the prior human time.

The second objection we want to consider is that our view is axiologically unmotivated: surely whatever being this is should not qualify as God, for it is not great enough..$^{8}$ The God of traditional theism, following Anselm, should be unsurpassable, such that no other being we can imagine is greater than God. But we can imagine, and in fact, have imagined, a being greater than the being described by the maximal God and fluctuating maximal God theses, namely, a being which possesses each of the great-making properties to their intrinsic maxima. Both the SMG and the FMG theses go astray in making a positive claim about the limitations on the great-making properties God has upfront, rather than stipulating that God will be greater than anything we can imagine and forcing us to push on preconceptions about metaphysical and logical possibility.

The former approach begins with a filled-out picture of the great-making properties or the maximal set. If someone rejects the picture in favour of another, she simply ends up endorsing a different conception of God. The result is that views of the conception of God, what it denotes, proliferate, and in response to certain objections we end up saying, "Well I just disagree about what God is." On the latter approach, we need only a very rough and ready picture of great-making properties to begin with and a broad consensus on how to make comparative judgments about the axiological value of such properties. As more arguments bring our attention to

\footnotetext{
${ }^{8}$ We are grateful to Mark Murphy for raising this objection.
} 
great-making properties or ways of thinking about them-what constitutes more power, more benevolence, more knowledge-we might then fill out the picture. But when we disagree, the disagreement is not about what God is but what is more valuable-what perfection in benevolence, or knowledge, or power consists in.

The FMG thesis may seem attractive to many precisely because they do not share axiological intuitions that have been taken for granted as though part of a broadly shared standard. It seems that literature by modern perfect being theologians assumed that immutability and impassibility, for instance, would make for a better rather than a worse kind of being. We simply mention here that many defenders of immutability and impassibility have not given arguments for this axiological assumption. Further, some theistic traditions regard a responsive and passible being as better than a being that is stoically unchanging. One upshot of considering the FMG thesis is that it invites us to focus more attention on arguments for hitherto unstated axiological assumptions about the greatest possible being.

\section{Conclusion}

This paper has shown that regarding Nagasawa's maximal God thesis through the lens of the recent move away from the timeless God provides more effective ways of responding to objections directed at perfect being theology. We have argued that the fluctuating maximal God thesis increases the explanatory power of Nagasawa's proposal. We believe that the FMG thesis provides new groundwork not only for articulating the relationship between divine attributes and time but also for furthering Nagasawa's methodology of responding to arguments against perfect being theism.

Acknowledgements We are grateful to Mark Murphy and Yujin Nagasawa for comments on earlier versions of this paper. The writing of this paper was partially supported by funding from a studentship hosted by the Arts and Humanities Research Council Doctoral Training Partnership and Pembroke College, Cambridge (Grant Number: AH/L503897/1, Grant Recipient: Matyáš Moravec).

Open Access This article is licensed under a Creative Commons Attribution 4.0 International License, which permits use, sharing, adaptation, distribution and reproduction in any medium or format, as long as you give appropriate credit to the original author(s) and the source, provide a link to the Creative Commons licence, and indicate if changes were made. The images or other third party material in this article are included in the article's Creative Commons licence, unless indicated otherwise in a credit line to the material. If material is not included in the article's Creative Commons licence and your intended use is not permitted by statutory regulation or exceeds the permitted use, you will need to obtain permission directly from the copyright holder. To view a copy of this licence, visit http://creativecommons.org/licen ses/by/4.0/.

\section{References}

Amini, M. (2016). Theological revisionism: From God to maximal God. Cogito, 8(2), 49-55.

Evans, C. S. (2009). Exploring kenotic christology. Vancouver: Regent College Publishing.

Felt, J. W. (1996). Why possible worlds aren't. The Review of Metaphysics, 50(1), 63-77.

Forrest, P. (2000). The incarnation: A philosophical case for kenosis. Religious Studies, 36(2), 127-140.

Kripke, S. (1981). Naming and necessity. Malden: Blackwell.

Lewis, D. (2002). On the plurality of worlds. Oxford: Blackwell Publishing. 
Morris, T. V. (1989). The metaphysics of God incarnate. In R. J. Feenstra (Ed.), Trinity, incarnation, and atonement (pp. 110-127). Notre Dame: University of Notre Dame Press.

Mullins, R. T. (2016). The end of the timeless God. Oxford: Oxford University Press.

Murphy, M. C. (2017). God's own ethics: Norms of divine agency and the argument from evil. Oxford: Oxford University Press.

Nagasawa, Y. (2017). Maximal God: A new defence of perfect being theism. Oxford: Oxford University Press.

Pawl, T. (2016). Temporary intrinsics and christological predication. In J. L. Kvanvig (Ed.), Oxford studies in philosophy of religion (Vol. 7, pp. 157-187). Oxford: Oxford University Press.

Robson, M. I. T. (2011). Possible worlds and the beauty of God. Religious Studies, 47, 479-492.

Swinburne, R. (2016). The coherence of theism (2nd ed.). Oxford: Oxford University Press.

Thompson, T. R. (2006). Nineteenth century kenotic christology. In C. S. Evans (Ed.), Exploring kenotic christology-The self-emptying of God (pp. 74-111). Oxford: Oxford University Press.

Publisher's Note Springer Nature remains neutral with regard to jurisdictional claims in published maps and institutional affiliations. 